\title{
Real-world Treatment Outcomes of the EXTREME Regimen as First-line Therapy for Recurrent/Metastatic Squamous Cell Carcinoma of the Head and Neck: A Multi-center Retrospective Cohort Study in Japan
}

\author{
DAISUKE SANO ${ }^{1}$, TAKUO FUJISAWA ${ }^{2}$, MOTOHIKO TOKUHISA ${ }^{3}$, \\ MINAKI SHIMIZU ${ }^{2}$, TOMOFUMI SAKAGAMI ${ }^{2}$, TAKASHI HATANO ${ }^{1}$, GOSHI NISHIMURA $^{1}$, \\ YASUSHI ICHIKAWA ${ }^{3}$, HIROSHI IWAI ${ }^{2}$ and NOBUHIKO ORIDATE ${ }^{1}$ \\ ${ }^{1}$ Department of Otorhinolaryngology, Head and Neck Surgery, \\ Yokohama City University, School of Medicine, Yokohama, Japan; \\ ${ }^{2}$ Department of Otorhinolaryngology, Head and Neck Surgery, Kansai Medical University, Osaka, Japan; \\ ${ }^{3}$ Department of Oncology, Yokohama City University, School of Medicine, Yokohama, Japan
}

\begin{abstract}
Background/Aim: This Japanese multiple-center retrospective study aimed to examine the real-world treatment outcomes of the EXTREME regimen as a first-line therapy for recurrent/metastatic squamous cell carcinoma of the head and neck (R/M SCCHN). Patients and Methods: A total of $100 \mathrm{R} / \mathrm{M} S \mathrm{SCHN}$ patients treated with the EXTREME regimen as first-line therapy were analyzed. The treatment outcomes were evaluated to compare patient and treatment characteristics with overall survival. Results: Patients treated with carboplatin-based EXTREME regimen showed similar overall survival with less adverse effects compared to that of patients using cisplatin. The postprogression survival was significantly longer in patients treated with second-line treatment following the EXTREME regimen than in those without second-line treatment. Conclusion: The carboplatin-based EXTREME regimen was more feasible with similar treatment outcomes compared to cisplatin-based EXTREME regimen. In addition, subsequent lines of therapy contributed to improvement of survival for R/M SCCHN patients.
\end{abstract}

This article is freely accessible online.

Correspondence to: Daisuke Sano, MD, Ph.D., Department of Head and Neck Surgery, Yokohama City University, School of Medicine 3-9 Fukuura, Kanazawa-ku, Yokohama, 236-0004, Japan. Tel: +81 457872687, Fax: +81 457832580, e-mail: dsano@yokohamacu.ac.jp

Key Words: EXTREME regimen, R/M SCCHN, nivolumab, platinum-refractory disease, post-progression survival.
Squamous cell carcinoma of the head and neck (SCCHN) consistently ranks as one of the 10 most frequently diagnosed cancers worldwide (1) and commonly presents with locally advanced disease. Despite advances in the diagnostic examinations and treatment modalities for patients with advanced SCCHN, $20 \%$ of patients with this disease develop distant metastatic lesions (2). The prognosis of patients with recurrent/metastatic SCCHN (R/M SCCHN) is generally poor with a median overall survival (OS) of <1 year (3-5). Therefore, their treatment is aimed at extending survival by maintaining a stable disease and controlling symptoms, thus improving patients' quality of life (QoL) (6). In 2008, Vermoken et al. demonstrated that adding cetuximab to cisplatin/carboplatin and 5-fluorouracil (5-FU) (the EXTREME regimen) significantly improved survival compared to platinum-based chemotherapy plus fluorouracil alone (10.1 months vs. 7.4 months) as the first-line treatment of R/M SCCHN in an open-label, randomized, multi-center, phase III study (7). The EXTREME regimen has been recommended as the standard of care for R/M SCCHN based on the National Comprehensive Cancer Network guidelines (8) as well as the 2018 Japanese Head and Neck Cancer Clinical Practice Guidelines (9). In an open-label, randomized, multi-center, phase III study known as CheckMate 141 trial, Ferris et al. reported that platinum-refractory R/M SCCHN patients treated with nivolumab, an anti-programmed cell death-1 (PD-1) antibody, showed improved survival, more favorable safety, and more stable QoL than those treated with standard single-agent therapy (10). Based upon the results of this trial $(10,11)$, nivolumab was approved in the United States for the treatment of R/M SCCHN patients and was approved in Japan for the treatment of those who previously received platinum-based therapy in 2017. Thus, the new 


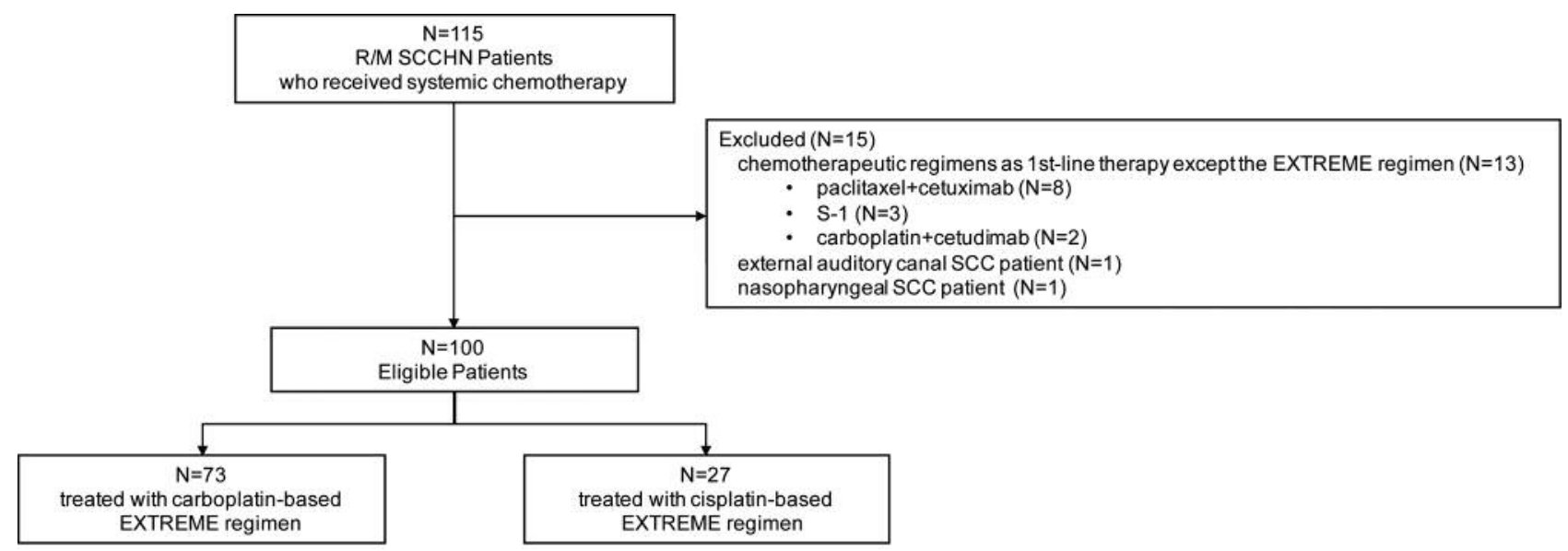

Figure 1. Patient selection flowchart.

treatment option including immuno-oncology (IO) agents, such as nivolumab, is currently used for the management of patients with R/M SCCHN. However, the real-world benefits of these therapies in Japanese patients with R/M SCCHN remain unclear. Herein, we aimed to conduct a multi-center retrospective cohort study to investigate real-world treatment outcomes of the EXTREME regimen as first-line therapy for Japanese patients with R/M SCCHN.

\section{Patients and Methods}

Study design. This multicenter retrospective cohort study was conducted between June 2013 and September 2018 at the Kansai Medical University Hospital, Osaka, Japan and Yokohama City University Hospital, Yokohama, Japan. The medical records of patients with R/M HNSCC who were treated with the EXTREME regimen as first-line therapy were reviewed retrospectively. The primary endpoint was overall survival (OS). The protocol was reviewed and approved by the Review Board of each institution (approval IDs: 2018249 and B181200001).

Patients. Patients with histologically confirmed SCCHN with recurrent or metastatic disease, who received systemic chemotherapy with the EXTREME regimen as first-line therapy, with an Eastern Cooperative Oncology Group performance status (ECOG PS) of 01 , aged 20 years or older, and with adequate hematologic, renal, and hepatic function were included. Patients who previously received systemic chemotherapy for recurrent or metastatic disease, or every chemotherapeutic regimen except the EXTREME regimen as firstline therapy were excluded. From the $115 \mathrm{R} / \mathrm{M} \mathrm{SCCHN}$ patients who received systemic chemotherapy, thirteen patients were excluded due to chemotherapeutic regimens except the EXTREME regimen as shown in Figure 1. One external auditory canal SCC patient and 1 nasopharyngeal SCC patient were also excluded. A total of $100 \mathrm{R} / \mathrm{M}$ HNSCC patients were eligible for this study. Platinum-refractory disease was defined as cancer with tumor progression during platinum-based treatment or recurrence within 6 months after platinum-based treatment (10). Tumor p16 expression was evaluated to determine the human-papilloma virus (HPV) infection status in patients with oropharyngeal SCC. All patients involved in this study were Japanese.

Treatment regimen. Patients were treated with either cisplatin (80 $\mathrm{mg} / \mathrm{m}^{2}$ body surface area as a 2 -h intravenous infusion on day 1 ) or carboplatin (with an area under the curve of $5 \mathrm{mg}$ per milliliter per minute, as a 1-hour intravenous infusion on day 1), 5-FU (800 $\mathrm{mg} / \mathrm{m}^{2}$ per day for 5 days under continuous infusion) every 3 weeks for six cycles, and cetuximab (at an initial dose of $400 \mathrm{mg} / \mathrm{m}^{2}$ given as a 2-hour intravenous infusion, followed by subsequent weekly doses of $250 \mathrm{mg} / \mathrm{m}^{2}$ given as a 1-hour intravenous infusion). This EXTREME regimen with a lower dosage of FP/FC regimen is thus used in this study, as this dosage for FP regimen is more commonly used in real-world clinical practice in Japan, and have been reported to have equal efficacy and better safety than the original FP regimen (cisplatin $100 \mathrm{mg} / \mathrm{m}^{2}$ day 1 and 5 -FU $1,000 \mathrm{mg} / \mathrm{m}^{2} / 24 \mathrm{~h}$ by continuous intravenous infusion on days 1 through 4 ), as described previously (12). The use of cisplatin or carboplatin was determined according to clinical recommendation (13), patient's fitness status and physician's discretion. After six or more cycles of chemotherapy, patients with stable disease received cetuximab monotherapy until disease progression or unacceptable toxicity as described previously (7).

Statistical analysis. The Chi-square and Wilcoxon-Mann-Whitney tests were used to examine the correlations between categorical variables. The progression-free survival (PFS) was defined as the period from the first disease relapse after the patients received the EXTREME regimen until death due to any cause. The postprogression survival (PPS), highly associated with OS after firstline chemotherapy in cancer patients, was defined as the time from the date of disease progression after starting the EXTREME regimen until death due to any cause $(14,15)$. OS, PFS and PPS were analyzed using the Kaplan-Meier method with the Wilcoxon log-rank test. Logistic regression analysis was used for univariate and multivariate comparisons. Statistical analysis was performed using JMP software (Version 12.2.0, SAS Institute Inc., Cary, NC, 
Table I. Clinical characteristics.

\begin{tabular}{|c|c|}
\hline Clinical characteristics & All patients $(\mathrm{N}=100)$ \\
\hline $\begin{array}{l}\text { Median age (range, in years) } \\
\text { Number of patients }(\mathrm{N})\end{array}$ & $67(25-82)$ \\
\hline \multicolumn{2}{|l|}{ Age } \\
\hline$\geq 67$ & 51 \\
\hline$<67$ & 49 \\
\hline \multicolumn{2}{|l|}{ Gender-N (percentage) } \\
\hline Male & 89 \\
\hline Female & 11 \\
\hline \multicolumn{2}{|l|}{ Performance status } \\
\hline ECOG 0 & 73 \\
\hline ECOG 1 & 27 \\
\hline \multicolumn{2}{|l|}{ Primary site } \\
\hline Hypopharynx & 39 \\
\hline Oropharynx & 17 \\
\hline p16 positive & 0 \\
\hline p16 negative & 5 \\
\hline Unknown & 12 \\
\hline Oral cavity & 24 \\
\hline Larynx & 12 \\
\hline Sinonasal & 5 \\
\hline Primary unknown & 3 \\
\hline \multicolumn{2}{|l|}{ Site of lesion } \\
\hline Locoregional recurrence only & 29 \\
\hline Distant metastasis only & 35 \\
\hline Locoregional and distant metastasis & 36 \\
\hline \multicolumn{2}{|l|}{ Multiple sites of lesion } \\
\hline Yes & 37 \\
\hline No & 63 \\
\hline \multicolumn{2}{|l|}{ Platinum-refractory disease } \\
\hline Yes & 19 \\
\hline No & 81 \\
\hline \multicolumn{2}{|l|}{ Previous treatment } \\
\hline Radiotherapy with cisplatin & 51 \\
\hline Others & 49 \\
\hline
\end{tabular}

ECOG, Eastern Cooperative Oncology Group.

USA) and the GraphPad Prism version 6.05 (GraphPad Software, San Diego, CA, USA). For all comparisons, a $p$-value $<0.05$ was considered significant.

\section{Results}

Patient characteristics. The clinical characteristics of the 100 $\mathrm{R} / \mathrm{M}$ HNSCC patients are summarized in Table I. The median age of patients was 67 years (range $=25-82$ years). Most patients were men $(89.0 \%)$, and had ECOG PS 0 $(73.0 \%)$. The primary sites of disease were as follows: hypopharynx $(39.0 \%)$, oral cavity $(24.0 \%)$, oropharynx (17.0\%, including 5 cases with p16-negative and 12 cases with unknown p16 status), larynx (12.0\%), sinonasal (5.0\%), and primary unknown $(3.0 \%)$. Twenty-nine patients had disease recurrence in the locoregional area, while 35 had distant metastasis. Thirty-seven patients had recurrent or
Table II. Treatment characteristics.

\begin{tabular}{lc}
\hline Treatment characteristics & Number of patients (N) \\
\hline Regimen & \\
CBDCA-use & 73 \\
CDDP-use & 27 \\
Median cycle of FP/FC regimen (range) & $4(1-16)$ \\
Cycles of FP/FC regimen & \\
$\geq 4$ & 54 \\
$<4$ & 46 \\
Reason to discontinue treatment & \\
by the EXTREME regimen & 59 \\
Progression disease & 29 \\
Adverse event & 12 \\
Others & \\
Median number of Cetuximab & $8-133)$ \\
maintenance (range) & \\
Cetuximab maintenance & 27 \\
Yes & 73 \\
No & \\
2nd-line treatment & 47 \\
Yes & 53 \\
No & \\
3rd-line treatment & 12 \\
Yes & 88 \\
No & \\
\hline
\end{tabular}

CBDCA, Carboplatin; CDDP, cisplatin; FP regimen, 5-fluorouracil plus platinum.

metastatic diseases in multiple sites. This data setting included 19 patients with platinum-refractory disease. Fiftyone patients underwent curative or postoperative chemoradiotherapy with cisplatin as previous treatment.

Treatment characteristics. Treatment characteristics are presented in Table II. A median of 4 (range=1-16) cycles of 5-fluorouracil and cisplatin (FP) or carboplatin (FC) were administered, and 54 patients were treated with $\geq 4$ cycles of FP/FC. Carboplatin was the preferred platinum-based therapy used in this study. The EXTREME regimen was discontinued in 59 and 29 patients due to disease progression and the occurrence of adverse events, respectively. The median number of cycles of cetuximab monotherapy administered after 6 or more cycles of chemotherapy was 8 (range=0-133), and 27 patients received cetuximab as maintenance therapy. About 47 patients received second-line treatment, while 12 received third-line treatment.

Treatment outcomes. As shown in Figure 2A and B, the median OS and PFS in the current study were 11 months and 5 months, and the 1-year OS and PFS were $44.6 \%$ and $24.4 \%$, respectively, which were comparable to the results of the previous EXTREME study. Univariate and multivariate analyses of clinical and treatment characteristics to determine 

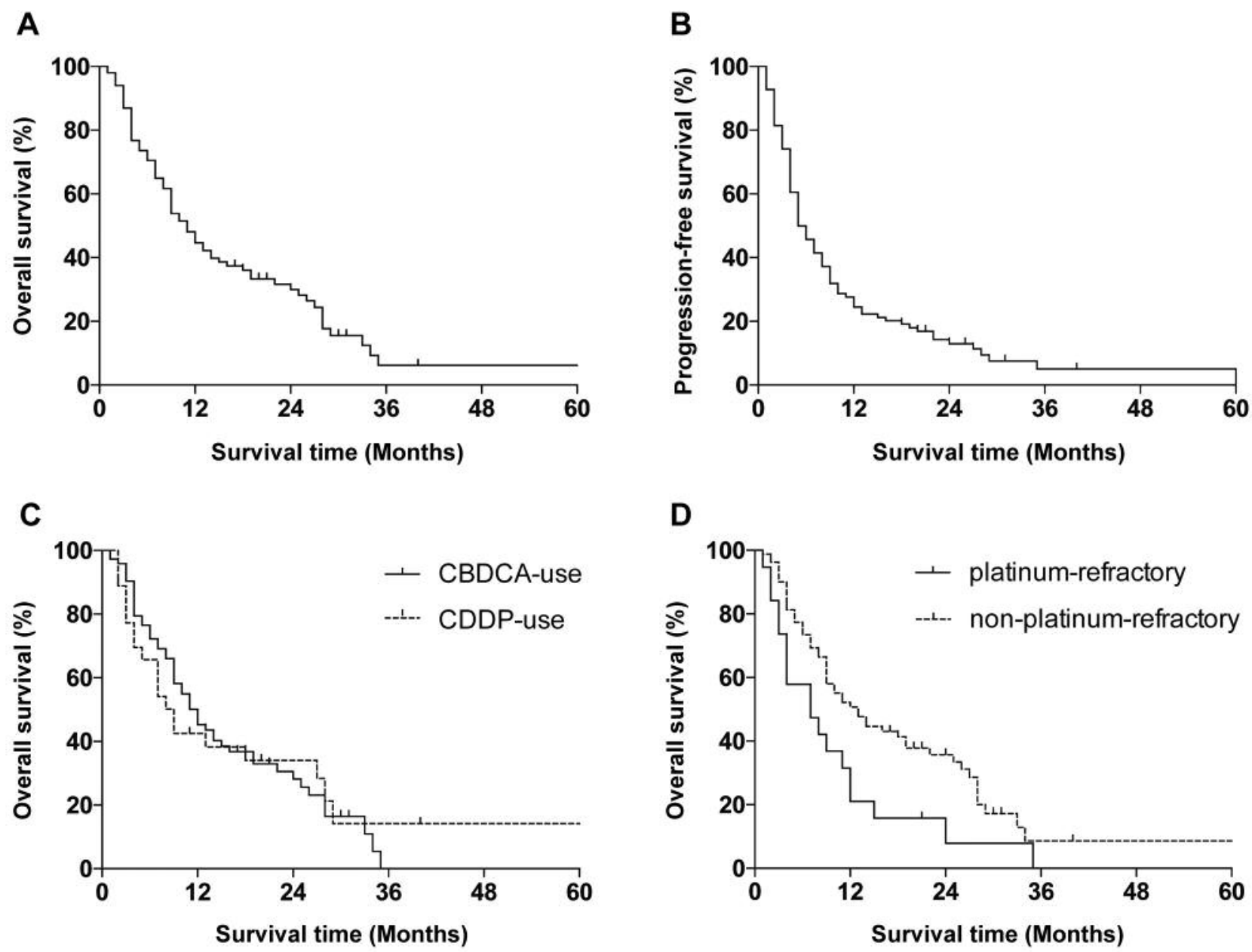

Figure 2. (A) Kaplan-Meier curves for OS of 100 R/M SCCHN patients. (B) Kaplan-Meier curves for PFS of 100 R/M SCCHN patients. (C) KaplanMeier curves for OS of patients using platinum agent. Black line: CBDCA-use group, dashed line: CDDP-use group; $p=0.980$. (D) Kaplan-Meier curves for OS of patients with platinum-refractory disease. Black line: platinum-refractory group, dashed line: non-platinum-refractory group; $p=0.018$.

the OS and PFS were performed as shown in Table III. Univariate analysis revealed that patients with platinumrefractory disease had poorer OS ( $p=0.02)$. By contrast, none of the factors were significantly associated with PFS. Multivariate analysis indicated that $\geq 4$ cycles of $\mathrm{FP} / \mathrm{FC}$ was an independent prognostic factor for OS $(p=0.006)$. KaplanMeier analysis revealed that there was no significant difference in OS between patients treated with carboplatin alone (CBDCA-use group) and those treated with cisplatin (CDDP-use group) (Figure 2C; median OS: 12 vs. 9 months; 1 -year OS rate $=45.3 \% v s .42 .5 \%$, respectively; $p=0.980$ ). In addition, patients with platinum-refractory disease had a shorter survival time than those without platinum-refractory disease (Figure 2D; median OS: 7 vs. 13 months; 1-year OS rate $=21.1 \% v s .50 .7 \%$, respectively; $p=0.018$ ).

The treatment outcomes of subsequent lines of therapy after the EXTREME regimen were assessed by the PPS. Kaplan-
Meier analysis revealed that patients treated with second-line treatment had a longer survival time than those without second-line treatment (Figure 3A; median PPS: 13 vs. 3 months; 1 -year PPS rate $=50.4 \%$ vs. $22.2 \%$, respectively; $p=0.001$ ). In addition, patients with platinum-refractory disease had a shorter PPS than those without platinumrefractory disease (Figure 3B; median PPS: 2 vs. 7 months; 1year PPS rate $=17.6 \% v s .40 .2 \%$, respectively; $p=0.049$ ). On the other hand, there was no significant difference in PPS between the CBDCA-use group and the CDDP-use group (Figure 3C; median PPS: 7 vs. 4 months; 1-year PPS rate $=37.3 \% v s .34 .7 \%$, respectively; $p=0.785$ ), and between patients treated with $\geq 4$ cycles of FP/FC and those with $4<$ cycles of FP/FC (Figure 3D; median PPS: 7 vs. 3 months; 1year PPS rate $=39.1 \%$ vs. $31.8 \%$, respectively; $p=0.276$ ). Twenty-eight patients received nivolumab as second-line treatment, while 3 received nivolumab as third-line treatment. 
Table III. Univariate and multivariate analyses of clinical and treatment characteristics for OS and PFS.

\begin{tabular}{|c|c|c|c|c|c|c|c|c|c|c|}
\hline & \multirow[b]{3}{*}{$\mathrm{N}$} & \multirow{2}{*}{\multicolumn{3}{|c|}{$\frac{\text { Univariate analysis }}{\text { Overall survival }}$}} & \multirow{2}{*}{\multicolumn{3}{|c|}{$\frac{\text { Univariate analysis }}{\text { Progression-free survival }}$}} & \multicolumn{3}{|c|}{ Multivariate analysis } \\
\hline & & & & & & & & \multicolumn{3}{|c|}{ Overall survival } \\
\hline & & Odds ratio & HR $(95 \%$ CI $)$ & $p$-Value & Odds ratio & HR (95\% CI) & $p$-Value & Odds ratio & $\mathrm{HR}(95 \% \mathrm{CI})$ & $p$-Value \\
\hline \multicolumn{11}{|l|}{ Age } \\
\hline$<67$ & 49 & 1 & Reference & 0.823 & 1 & Reference & 1 & & & \\
\hline$\geq 67$ & 51 & 1.169 & 0.483 to 2.829 & & 1.045 & 0.283 to 3.862 & & & & \\
\hline \multicolumn{11}{|l|}{ Gender } \\
\hline Female & 11 & 1 & Reference & 0.482 & 1 & Reference & 0.889 & & & \\
\hline Male & 89 & 1.64 & 0.439 to 6.120 & & 0.911 & 0.102 to 7.770 & & & & \\
\hline \multicolumn{11}{|l|}{ Performance status } \\
\hline ECOG 0 & 73 & 1 & Reference & 1 & 1 & Reference & 0.058 & & & \\
\hline ECOG 1 & 27 & 1.078 & 0.396 to 2.939 & & NA & NA & & & & \\
\hline \multicolumn{11}{|l|}{ Site of lesion } \\
\hline Others & 71 & 1 & Reference & 0.46 & 1 & Reference & 0.176 & & & \\
\hline Locoregional recurrence only & 29 & 1.61 & 0.573 to 4.523 & & 0.948 & 0.227 to 3.950 & & & & \\
\hline \multicolumn{11}{|l|}{ Multiple sites of lesion } \\
\hline No & 63 & 1 & Reference & 0.101 & 1 & Reference & 0.089 & 1 & Reference & 0.488 \\
\hline Yes & 37 & 2.583 & 0.932 to 7.158 & & 6 & 0.728 to 49.42 & & 1.182 & 0.733 to 1.885 & \\
\hline \multicolumn{11}{|l|}{ Previous treatment } \\
\hline Others & 49 & 1 & Reference & 0.502 & 1 & Reference & 0.521 & & & \\
\hline Radiotherapy with CDDP & 51 & 1.434 & 0.590 to 3.483 & & 1.64 & 0.433 to 6.206 & & & & \\
\hline \multicolumn{11}{|l|}{ Regimen } \\
\hline CDDP-use & 27 & 1 & Reference & 1 & 1 & Reference & 0.142 & & & \\
\hline CBDCA-use & 73 & 0.928 & 0.340 to 2.528 & & 3.091 & 0.818 to 11.68 & & & & \\
\hline \multicolumn{11}{|l|}{ Platinum-refractory disease } \\
\hline No & 81 & 1 & Reference & 0.020 & 1 & Reference & 0.201 & 1 & Reference & 0.104 \\
\hline Yes & 19 & 8.509 & 1.077 to 67.23 & & NA & NA & & 1.609 & 0.903 to 2.738 & \\
\hline \multicolumn{11}{|l|}{ Cycles of FP/FC regimen } \\
\hline$<4$ & 46 & 1 & Reference & 0.070 & 1 & Reference & 1 & 1 & Reference & 0.006 \\
\hline$\geq 4$ & 54 & 0.388 & 0.151 to 0.998 & & 1.195 & 0.323 to 4.417 & & 0.511 & 0.317 to 0821 & \\
\hline \multicolumn{11}{|l|}{ Cetuximab maintenance } \\
\hline No & 73 & 1 & Reference & 0.207 & 1 & Reference & 0.452 & & & \\
\hline Yes & 27 & 0.516 & 0.199 to 1.336 & & 0.515 & 0.133 to 1.988 & & & & \\
\hline
\end{tabular}

ECOG, Eastern Cooperative Oncology Group; CBDCA, carboplatin; CDDP, cisplatin; FP regimen, 5-fluorouracil plus platinum; FC regimen, 5fluorouracil plus carboplatin; HR, hazard ratio; $\mathrm{CI}$, confidence interval.

The median PPS of patients treated with nivolumab as second or third-line treatment was 20 months, as shown in Figure 3E.

Treatment characteristics according to the platinum agents used in the EXTREME regimen are summarized in Table IV. As shown in Table V, Chi-square tests revealed that the number of patients in the CBDCA-use group who developed adverse effects as the reason to discontinue the EXTREME regimen was significantly smaller than those in the CDDP-use group $(p=0.001)$. Patients in the CBDCA-use group received an average of 4 cycles of FP/FC, while those in the CDDP-use group received an average of 3 cycles of FP/FC ( $p=0.089)$.

Lastly, treatment characteristics according to patients received second-line treatment after the EXTREME regimen are summarized in Table V. Patients with second-line treatment included significantly more patients who had ECOG PS0 compared to those without second-line treatment $(p=0.043)$. A significant difference was also observed in the median cycle of FP/FC treatment between patients with second-line treatment and those without second-line treatment ( 5 and 3 , respectively, $p=0.003$ ). In addition, patients with second-line treatment had a smaller number of patients who developed adverse events, which was the reason for discontinuing the treatment, than those without second-line treatment $(p=0.009)$.

\section{Discussion}

In this study, we present the result of a multiple-center retrospective cohort study to determine the real-world treatment outcomes of the EXTREME regimen as first-line therapy for Japanese patients with R/M SCCHN. As it is well known that $\mathrm{R} / \mathrm{M} \mathrm{SCCHN}$ patients with platinum-refractory 


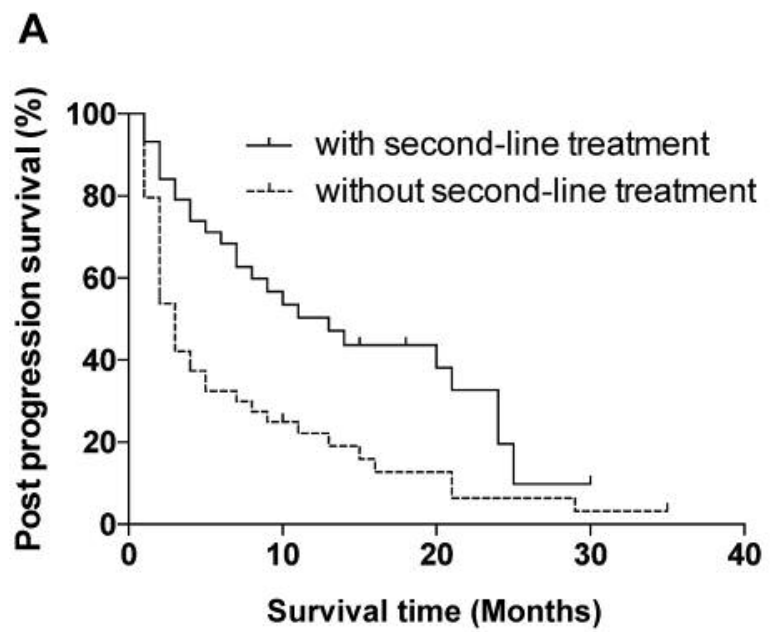

B
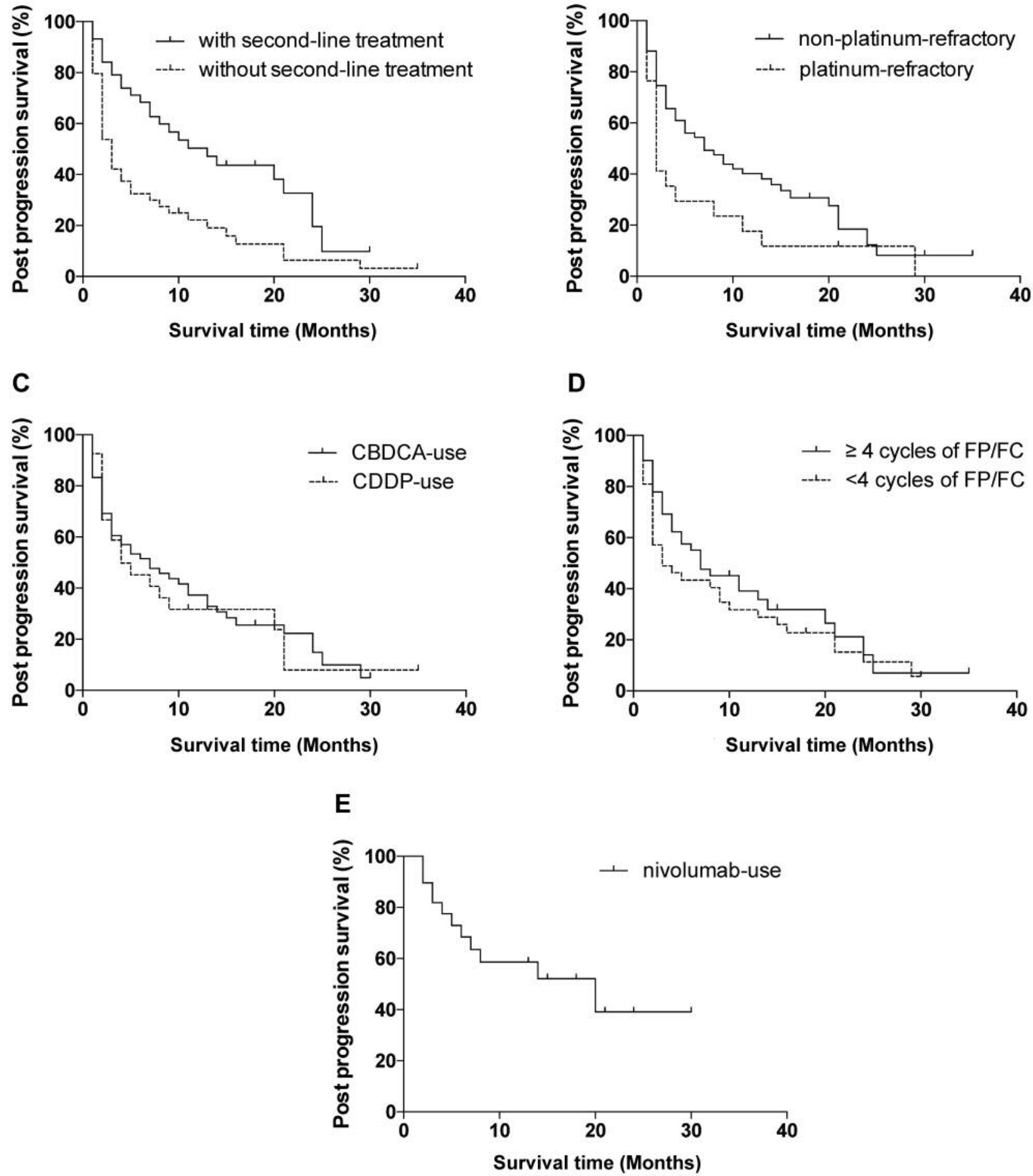

Figure 3. (A) Kaplan-Meier curves for PPS of patients with or without second-line treatment. Black line: with second-line treatment group, dashed line: without second-line treatment group; $p=0.001$. (B) Kaplan-Meier curves for PPS of patients with platinum-refractory disease. Black line: platinum-refractory group, dashed line: non-platinum-refractory group; $p=0.049$. (C) Kaplan-Meier curves for PPS of patients using platinum agent. Black line: CBDCA-use group, dashed line: CDDP-use group; $p=0.785$. (D) Kaplan-Meier curves for PPS of patients for cycles of FP/FC. Black line: $\geq 4$ cycles of FP/FC group, dashed line: $<4$ cycles of FP/FC group; $p=0.276$. (E) Kaplan-Meier curves for PPS of patients treated with nivolumab as second or third-line treatment. 
Table IV. Characteristics of platinum-based treatment used in the EXTREME regimen.

\begin{tabular}{|c|c|c|c|}
\hline & \multicolumn{2}{|c|}{ All patients $(\mathrm{N}=100)$} & \multirow[b]{2}{*}{$p$-Value } \\
\hline & Carboplatin only & Cisplatin use & \\
\hline Number of patients $(\mathrm{N})$ & 73 & 27 & \\
\hline Median age* & 68 & 64 & $0.063^{*}$ \\
\hline \multicolumn{4}{|l|}{ Gender-N (percentage) } \\
\hline Female & 10 & 1 & \multirow[t]{2}{*}{0.279} \\
\hline Male & 63 & 26 & \\
\hline \multicolumn{4}{|l|}{ Performance status } \\
\hline ECOG 0 & 56 & 17 & \multirow[t]{2}{*}{0.207} \\
\hline ECOG 1 & 17 & 10 & \\
\hline \multicolumn{4}{|l|}{ Multiple sites of lesion } \\
\hline No & 49 & 14 & \multirow[t]{2}{*}{0.171} \\
\hline Yes & 24 & 13 & \\
\hline \multicolumn{4}{|l|}{ Site of lesion } \\
\hline Locoregional recurrence only & 22 & 7 & \multirow[t]{2}{*}{0.806} \\
\hline Others & 51 & 20 & \\
\hline \multicolumn{4}{|l|}{ Previous treatment } \\
\hline CDDP-RT & 35 & 16 & \multirow[t]{2}{*}{0.371} \\
\hline Others & 38 & 11 & \\
\hline \multicolumn{4}{|l|}{ Platinum-refractory disease } \\
\hline No & 60 & 21 & \multirow[t]{2}{*}{0.775} \\
\hline Yes & 13 & 6 & \\
\hline Median cycle of FP/FC regimen (range) & 4 & 3 & $0.089^{*}$ \\
\hline \multicolumn{4}{|l|}{ Reason to discontinue treatment by EXTREME regimen } \\
\hline Adverse event & 15 & 14 & \multirow[t]{3}{*}{$0.001 * *$} \\
\hline Progression disease & 49 & 10 & \\
\hline Others & 10 & 2 & \\
\hline Median number of Cetuximab maintenance (range)* & 8 & 6 & 0.362 \\
\hline \multicolumn{4}{|l|}{ Cetuximab maintenance } \\
\hline No & 53 & 20 & \multirow[t]{2}{*}{1} \\
\hline Yes & 20 & 7 & \\
\hline \multicolumn{4}{|l|}{ 2nd-line treatment } \\
\hline No & 36 & 17 & \multirow[t]{2}{*}{0.264} \\
\hline Yes & 37 & 10 & \\
\hline \multicolumn{4}{|l|}{ 3rd-line treatment } \\
\hline No & 62 & 26 & \multirow[t]{2}{*}{0.172} \\
\hline Yes & 11 & 1 & \\
\hline
\end{tabular}

*Mann-Whitney $U$-test. **Adverse effect $v s$. others. CBDCA, Carboplatin; CDDP, cisplatin; ECOG, Eastern Cooperative Oncology Group; FP regimen, 5-fluorouracil plus platinum.

disease have a median OS of $<6$ months (16) until the use of nivolumab was approved, our study confirmed that patients with platinum-refractory disease showed poorer OS than those with non-platinum-refractory disease regardless of pretreatment modalities. While the present study only included a small number of R/M HNSCC patients, these results suggested that R/M SCCHN patients should be carefully assessed for platinum sensitivity so that appropriate first-line therapy can be provided.

The OS of our study patients was comparable to that of the previous EXTREME study, even though the present study included more than $70 \%$ of patients who received the EXTREME regimen with carboplatin instead of cisplatin.
Surprisingly, we determined that the EXTREME regimen using carboplatin showed survival outcomes similar to that using cisplatin; however, de Mello et al. reported that the OS of the CDDP-use group was significantly longer than that of the CBDCA-use group in their single institutional retrospective study (17). The results of the subgroup assessment in the EXTREME trial also showed that patients who received the EXTREME regimen using carboplatin did not show a better OS compared to those treated with the EXTREME regimen using cisplatin (7). These differences might be due to the dosage of chemotherapeutic agents used, as the dose of CBDCA was same as that in the EXTREME study, while the dose of CDDP was reduced in the present 
Table V. Characteristics of patients who received second-line treatment.

\begin{tabular}{|c|c|c|c|}
\hline & \multicolumn{2}{|c|}{ Second line treatment } & \multirow[b]{2}{*}{$p$-Value } \\
\hline & Yes & No & \\
\hline Number of patients $(\mathrm{N})$ & 47 & 53 & \\
\hline Median age* & 66 & 68 & 0.068 \\
\hline \multicolumn{4}{|l|}{ Gender-N (percentage) } \\
\hline Female & 5 & 6 & \multirow[t]{2}{*}{1} \\
\hline Male & 42 & 47 & \\
\hline \multicolumn{4}{|l|}{ Performance status } \\
\hline ECOG 0 & 39 & 34 & \multirow[t]{2}{*}{0.043} \\
\hline ECOG 1 & 8 & 19 & \\
\hline \multicolumn{4}{|l|}{ Multiple sites of lesion } \\
\hline No & 29 & 34 & \multirow[t]{2}{*}{0.838} \\
\hline Yes & 18 & 19 & \\
\hline \multicolumn{4}{|l|}{ Site of lesion } \\
\hline Locoregional recurrence only & 12 & 17 & \multirow[t]{2}{*}{0.514} \\
\hline Others & 35 & 36 & \\
\hline \multicolumn{4}{|l|}{ Previous treatment } \\
\hline CDDP-RT & 27 & 24 & \multirow[t]{2}{*}{0.237} \\
\hline Others & 20 & 29 & \\
\hline \multicolumn{4}{|l|}{ Platinum-refractory disease } \\
\hline No & 39 & 42 & \multirow[t]{2}{*}{0.799} \\
\hline Yes & 8 & 11 & \\
\hline \multicolumn{3}{|l|}{ Median cycle of FP/FC } & 0.003 \\
\hline \multicolumn{4}{|l|}{$\begin{array}{l}\text { Reason to discontinue treatment } \\
\text { by EXTREME regimen }\end{array}$} \\
\hline Adverse effect & 8 & 22 & \multirow[t]{3}{*}{$0.009^{* *}$} \\
\hline Progression disease & 36 & 23 & \\
\hline Others & 3 & 8 & \\
\hline \multicolumn{4}{|l|}{ Median number of Cetuximab } \\
\hline \multicolumn{4}{|l|}{ Cetuximab maintenance } \\
\hline No & 34 & 39 & \multirow[t]{2}{*}{1} \\
\hline Yes & 13 & 14 & \\
\hline
\end{tabular}

*Mann-Whitney $U$-test. **Adverse effect $v s$. others. ECOG, Eastern Cooperative Oncology Group; FP regimen, 5-fluorouracil plus platinum.

study. The racial differences between Asian and Western populations, especially in terms of susceptibility to chemotherapy agents observed in the Japanese population $(18,19)$, also might have affected the results of patients who received the EXTREME regimen using carboplatin. Patients in the CBDCA-use group received more cycles of chemotherapy and developed less adverse effects, which was the reason why the EXTREME regimen treatment was discontinued, than those in the CDDP-use group, suggesting that carboplatin-based EXTREME regimen could be acceptable for R/M SCCHN patients who may not tolerate cisplatin because of poor performance status or other comorbidities. However, we need to pay attention to the possibility of bias in point of this issue, as the present study did not include detailed information of adverse events related the EXTREME regimen in this study.
The present study indicated that subsequent line treatment after the EXTREME regimen had significantly improved the survival of patients with R/M SCCHN. This might be mainly because those patients included R/M SCCHN patients who received nivolumab as second or third-line treatment, showing good prognosis with the median PPS of 20 months in this study, comparable to that of the previous CheckMate 141 trial (10). In addition, our results indicated that patients who received second-line treatment in our data set potentially included more favorable patients with well-controlled $\mathrm{R} / \mathrm{M}$ disease by the EXTREME regimen. This might also affect the good prognosis in those patients. By contrast, neither the platinum agents for the EXTREME regimen nor the number of cycles of FP/FC impacted the results of PPS in the present study, suggesting that the treatment outcomes of subsequent lines of therapy after the EXTREME regimen might be less affected by the details of the EXTREME regimen. Interestingly, R/M SCCHN patients with platinum-refractory also showed poor PPS in this study. Our data set included only two platinum-refractory R/M SCCHN patients treated with nivolumab, something that might affect this result.

Another limitation of the present study is that our retrospective study comprised of a small number of $\mathrm{R} / \mathrm{M}$ SCCHN patients recruited from only two institutions. Various patient backgrounds might have potentially biases affecting the results of our analysis. In addition, our dataset included many R/M SCCHN patients treated with the EXTREME regimen using carboplatin, which affected some survival results. To confirm the findings of this study, further multi-institutional studies in Asian countries are warranted.

In conclusion, this retrospective cohort study showed that the carboplatin-based EXTREME regimen was feasible and treatment outcomes were similar to cisplatin-based EXTREME regimen as first-line therapy for Japanese R/M SCCHN patients. We also confirmed that R/M SCCHN patients with platinum-refractory disease had a poorer prognosis. Finally, we determined that treatment outcomes of subsequent lines of therapy, including nivolumab, improved the survival of patients with R/M SCCHN pretreated with the EXTREME regimen. Future analysis using a larger multi-institutional study should be warranted to validate the usability of our results.

\section{Conflicts of Interest}

The Authors declare that they have no competing interests.

\section{Authors' Contributions}

DS, TF, MT, HI and NO designed the study. DS wrote the main manuscript text and prepared the Figure. DS, TF, MT, MS, TS, TH and GN were involved with data collection. DS and NO performed the analysis. YI, HI and NO provided project supervision. All Authors discussed the results of the study, made comments on the manuscript, and gave final approval of the version to be published. 


\section{References}

1 Torre LA, Bray F, Siegel RL, Ferlay J, Lortet-Tieulent J and Jemal A: Global cancer statistics, 2012. CA Cancer J Clin 65(2): 87-108, 2015. PMID: 25651787. DOI: 10.3322/caac.21262

2 Specenier PM and Vermorken JB: Recurrent head and neck cancer: Current treatment and future prospects. Expert Rev Anticancer Ther 8(3): 375-391, 2008. PMID: 18366286. DOI: 10.1586/14737140.8.3.375

3 Price KA and Cohen EE: Current treatment options for metastatic head and neck cancer. Curr Treat Options Oncol 13(1): 35-46, 2012. PMID: 22252884. DOI: 10.1007/s11864011-0176-y

4 Wiegand S, Zimmermann A, Wilhelm $\mathrm{T}$ and Werner JA: Survival after distant metastasis in head and neck cancer. Anticancer Res 35(10): 5499-5502, 2015. PMID: 26408715.

5 Dang RP, Le VH, Miles BA, Teng MS, Genden EM, Bakst RL, Gupta V, Zhang DY, Demicco EG, Posner MR and Misiukiewicz KJ: Clinical outcomes in patients with recurrent or metastatic human papilloma virus-positive head and neck cancer. Anticancer Res 36(4): 1703-1709, 2016. PMID: 27069149.

6 Peyrade F, Cupissol D, Geoffrois L, Rolland F, Borel C, Ciais $\mathrm{C}$, Faivre $\mathrm{S}$ and Guigay $\mathrm{J}$ : Systemic treatment and medical management of metastatic squamous cell carcinoma of the head and neck: Review of the literature and proposal for management changes. Oral Oncol 49(6): 482-491, 2013. PMID: 23415727. DOI: $10.1016 /$ j.oraloncology.2013.01.005

7 Vermorken JB, Mesia R, Rivera F, Remenar E, Kawecki A, Rottey S, Erfan J, Zabolotnyy D, Kienzer HR, Cupissol D, Peyrade F, Benasso M, Vynnychenko I, De Raucourt D, Bokemeyer C, Schueler A, Amellal N and Hitt R: Platinumbased chemotherapy plus cetuximab in head and neck cancer. $\mathrm{N}$ Engl J Med 359(11): 1116-1127, 2008. PMID: 18784101. DOI: 10.1056/NEJMoa0802656

8 Colevas AD, Yom SS, Pfister DG, Spencer S, Adelstein D, Adkins D, Brizel DM, Burtness B, Busse PM, Caudell JJ, Cmelak AJ, Eisele DW, Fenton M, Foote RL, Gilbert J, Gillison ML, Haddad RI, Hicks WL, Hitchcock YJ, Jimeno A, Leizman D, Maghami E, Mell LK, Mittal BB, Pinto HA, Ridge JA, Rocco J, Rodriguez CP, Shah JP, Weber RS, Witek M, Worden F, Zhen W, Burns JL and Darlow SD: Nccn guidelines insights: Head and neck cancers, version 1.2018. J Natl Compr Canc Netw 16(5): 479-490, 2018. PMID: 29752322. DOI: 10.6004/ jnccn.2018.0026

9 Nibu KI, Hayashi R, Asakage T, Ojiri H, Kimata Y, Kodaira T, Nagao T, Nakashima T, Fujii T, Fujii H, Homma A, Matsuura K, Monden N, Beppu T, Hanai N, Kirita T, Kamei Y, Otsuki N, Kiyota N, Zenda S, Omura K, Omori K, Akimoto T, Kawabata K, Kishimoto S, Kitano H, Tohnai I and Nakatsuka T: Japanese clinical practice guideline for head and neck cancer. Auris Nasus Larynx 44(4): 375-380, 2017. PMID: 28325607. DOI: 10.1016/j.anl.2017.02.004

10 Ferris RL, Blumenschein G, Jr., Fayette J, Guigay J, Colevas AD, Licitra L, Harrington K, Kasper S, Vokes EE, Even C, Worden F, Saba NF, Iglesias Docampo LC, Haddad R, Rordorf T, Kiyota N, Tahara M, Monga M, Lynch M, Geese WJ, Kopit J, Shaw JW and Gillison ML: Nivolumab for recurrent squamous-cell carcinoma of the head and neck. N Engl J Med 375(19): 1856-1867, 2016. PMID: 27718784. DOI: 10.1056/ NEJMoa1602252
11 Kiyota N, Hasegawa Y, Takahashi S, Yokota T, Yen CJ, Iwae S, Shimizu Y, Hong RL, Goto M, Kang JH, Sum Kenneth Li W, Ferris RL, Gillison M, Namba Y, Monga M, Lynch M and Tahara M: A randomized, open-label, phase III clinical trial of nivolumab vs. Therapy of investigator's choice in recurrent squamous cell carcinoma of the head and neck: A subanalysis of asian patients versus the global population in checkmate 141 . Oral Oncol 73: 138-146, 2017. PMID: 28939066. DOI: 10.1016/j.oraloncology.2017.07.023

12 Kiyota N, Tahara M, Kadowaki S, Fuse N, Doi T, Minami H and Ohtsu A: Systemic chemotherapy with cisplatin plus 5-fu (pf) for recurrent or metastatic squamous cell carcinoma of the head and neck ( $\mathrm{r} / \mathrm{m}$ scchn): Efficacy and safety of a lower dose of pf (80/800) at a single institution in japan. Jpn J Clin Oncol 39(4): 225-230, 2009. PMID: 19211574. DOI: 10.1093/jjco/hyp002

13 Ahn MJ, D'Cruz A, Vermorken JB, Chen JP, Chitapanarux I, Dang HQ, Guminski A, Kannarunimit D, Lin TY, Ng WT, Park KU and Chan AT: Clinical recommendations for defining platinum unsuitable head and neck cancer patient populations on chemoradiotherapy: A literature review. Oral Oncol 53: 10-16, 2016. PMID: 26712252. DOI: 10.1016/j.oraloncology.2015.11.019

14 Broglio KR and Berry DA: Detecting an overall survival benefit that is derived from progression-free survival. J Natl Cancer Inst 101(23): 1642-1649, 2009. PMID: 19903805. DOI: 10.1093/ jnci/djp369

15 Imai H, Kaira K and Minato K: Clinical significance of postprogression survival in lung cancer. Thorac Cancer 8(5): 379386, 2017. PMID: 28627767. DOI: 10.1111/1759-7714.12463

16 Saloura V, Cohen EE, Licitra L, Billan S, Dinis J, Lisby S and Gauler TC: An open-label single-arm, phase ii trial of zalutumumab, a human monoclonal anti-egfr antibody, in patients with platinum-refractory squamous cell carcinoma of the head and neck. Cancer Chemother Pharmacol 73(6): 1227-1239, 2014. PMID: 24714973. DOI: 10.1007/s00280-014-2459-z

17 de Mello RA, Geros S, Alves MP, Moreira F, Avezedo I and Dinis J: Cetuximab plus platinum-based chemotherapy in head and neck squamous cell carcinoma: A retrospective study in a single comprehensive european cancer institution. PLoS One 9(2): e86697, 2014. PMID: 24516537. DOI: 10.1371/journal. pone. 0086697

18 Nishimura G, Tsukuda M, Horiuchi C, Satake K, Yoshida T, Taguchi T, Nagao J, Kawakami M, Kondo N, Matsuda H and Mikami Y: Decrease of creatinine clearance rate with aging in patients with head and neck cancer in japan. Int J Clin Oncol 12(2): 120-124, 2007. PMID: 17443279. DOI: 10.1007/s10147006-0635-9

19 Kenmotsu H and Tanigawara Y: Pharmacokinetics, dynamics and toxicity of docetaxel: Why the japanese dose differs from the western dose. Cancer Sci 106(5): 497-504, 2015. PMID: 25728850. DOI: $10.1111 /$ cas. 12647
Received October 16, 2019

Revised November 13, 2019

Accepted November 14, 2019 